\title{
Role of biomass gasification in petrochemical industry: A mini review
}

\author{
Debarpita Ghosal* and Vivek Kumar Singh \\ Department of Chemical Engineering, CV Raman College of Engineering, India \\ *Corresponding author: Debarpita Ghosal, Department of Chemical Engineering, C.V. Raman College of Engineering, Bhubaneswar, India.
}

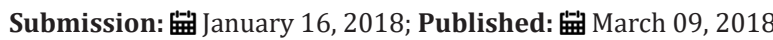

\section{Introduction}

Biomass offers a resource of carbon from the biosphere as a different to fossilized carbon laid down tens of millions of years ago. Anything that grows and is available in non-fossilized form can be classified as biomass, including arable crops, trees, bushes, animal by-products, human and animal waste, waste food and any other waste stream that rots quickly and it can be replenish on a rolling time of years or decades.

\section{Thermo-chemical Routes to Converting Biomass}

\section{Gasification}

Thermo-chemical conversion routes are based on biomass gasification [1-3]. Gasification is a partial combustion process in which biomass reacts at a high temperature with oxygen, which is supplied at levels insufficient to support full combustion. The outputs are a gas (the desired product) and a solid ash residue whose composition depends on the type of biomass. Continuous gasification processes for various feed stocks have been under development since the early 1930s. Preferably, the gas produced would be a mixture of hydrogen and carbon monoxide, but, in practice, it also contains methane, $\mathrm{CO} 2$ and a range of contaminants. The gas produced tends to be called syngas (or synthesis gas) although some people prefer to reserve that term for a blend of hydrogen and carbon monoxide alone. A variety of gasification technologies is available across a range of sizes, from small updraft and downdraft gasifiers through a range of fluidized bed gasifiers at an intermediate scale and on to larger entrained flow and plasma gasifiers [1,4]. (In an updraft gasifier, the oxidant is blown up through the fixed gasifier bed with the syngas exiting at the top; in a downdraft gasifier, the oxidant is blown down through the reactor with the syngas exiting at the bottom.) Gasification processes tend to operate either above the ash melting temperature (typically.1200 ${ }^{\circ} \mathrm{C}$ ) or below the ash melting temperature. In the higher temperature processes, there is little methane or tar formation. There is a choice between oxygen or air as the oxidant, and some choice over operating pressure. E4Tech [5] have published a report on the experimental and commercial deployment of gasification technology. From this, it can be seen that the question of which gasification technology is 'best' depends on whether the priority is to minimize cost, maximize reliability, produce a very pure syngas, handle a wide range of feedstock types, avoid pre-processing of biomass or operate at a large scale [6]. Several demonstration projects have been implemented around the world to show how gasifiers can, when designed right, operate reliably either in isolation or in conjunction with a downstream conversion process. By contrast, the largest gasifiers in the world (which are more than 300 times bigger than the Gussing demonstration plant) tend to be found in more straightforward applications such as large scale conversion of low-value streams on oil refineries into raw syngas for power generation [7]. If the scale of interest is around one million tonnes of refined product per year, the biomass feedstock required will be of the order of six million tonnes per year, which equates to 8000 oven-dry tonnes per day or $2500 \mathrm{MW}$ th. At the current state of gasifier technology development, this tends to imply entrained flow gasifiers or possibly circulating fluidized bed gasifiers depending on the number of gasification units desired as part of a cost-versus-reliability optimization [1]. The entrained flow gasifier offers economies of scale because it can run at feed rates of up to 10,000 oven-dry tonnes per day, but it requires a highly processed feedstock to compensate for the very short residence time in the gasification reactor a matter of seconds. One option is to grind the biomass to achieve a particle size of less than $1 \mathrm{~mm}$, which, for a fibrous-vegetable-based feedstock, may require an upstream torrefaction step to make it rsfs.royalsocietypublishing. org Interface Focus 3: 201200383 grindable [1]. (Torre faction is a heat-treatment process carried out in the absence of added oxygen at temperatures around $250^{\circ} \mathrm{C}$, converting biomass into a charcoallike material which retains $90 \%$ of its original energy content.)

Another option for feedstock processing is to convert the biomass into pyrolysis oil via a fast pyrolysis step and inject it as a fine spray into the gasifier. Pyrolysis is a thermal conversion process in which no oxygen is added [8]. Entrained flow gasifiers operate at high temperature (1200-1600 $\left.{ }^{\circ} \mathrm{C}\right)$, usually on oxygen, and at pressure of up to 100 bar [9]. The circulating fluidized bed gasifier can handle a more variable feedstock slate provided the particle size is kept below $20 \mathrm{~mm}$. It operates below the ash melting point and offers the option of pressurized operation to facilitate 
running at up to 1800 oven-dry tonnes per day. It is usually blown by air rather than oxygen because of the large volumes of gas required to keep the biomass and the inert bed material in a fluidized state. A major attraction of syngas is the very wide range of potential uses [10]. Broadly speaking, there are four options for converting syngas into useful downstream products: FischerTropsch synthesis of hydrocarbon chains, methanol synthesis, mixed alcohol synthesis and syngas fermentation [5]. The FischerTropsch process was developed in the 1920s to produce an alternative to conventional diesel fuel [11]. It has been deployed in South Africa, Germany and elsewhere for synthesizing transport fuels and petrochemical feed stocks, often in circumstances of economic or political necessity [12]. By choosing an appropriate catalyst (usually based on iron or cobalt) and appropriate reaction conditions (usually $200-350{ }^{\circ} \mathrm{C}$ and $20-40$ bar), the process with its associated cracking and separation stages can be optimized to produce heavy waxes for conversion to diesel, light olefins for gasoline, naphtha for petrochemicals production or methane as a replacement for natural gas [13]. The ideal Fischer-Tropsch feedstock is a syngas consisting of a mixture of hydrogen and carbon monoxide with a molar ratio of 2:1 [14]. Methanol synthesis is another attractive conversion route, because methanol is one of the top 10 petrochemical commodities traded internationally [13]. Syngas can be converted into methanol over a copper-zinc oxide catalyst at $220-300{ }^{\circ} \mathrm{C}$ and 50-100 bar [14]. Methanol, in turn, can be used to make acetic acid, formaldehyde for resins, petrol additives and petrochemical building blocks such as ethylene and propylene [13]. Under slightly more aggressive process conditions (up to $425^{\circ} \mathrm{C}$ and 300 bar), a wider range of mixed alcohols can be produced [14], which opens up a wider potential product slate. The processes use catalysts modified from either Fischer-Tropsch synthesis or methanol synthesis, by addition of alkali metals. Finally, the syngas fermentation route uses biochemical processes and reaction conditions that are close to ambient temperature and pressure to make ethanol or other alcohols. Biochemical processes are addressed below. The National Renewable Energy Laboratory has listed 16 different end-uses for syngas, which (in addition to those listed above) include producing hydrogen, ammonia (which is the second largest synthetic chemical in the world), di-methyl ether (for use as a refrigerant or a chemical feedstock), acetic acid, formaldehyde, methyl tertiary butyl ether, olefins and gasoline [13]. There are many options for converting biomass syngas into petrochemical feed stocks. Consider, for example, the olefins conversion chain in which ethylene and propylene are converted into polymers (polyethylene, polypropylene, PVC), glycols (ethylene glycol, propylene glycol) and a range of familiar materials such as acetone, acetic acid, petrol additives and surfactants. The olefins can be produced by synthesizing naphtha in a Fischer-Tropsch process and then cracking it in a conventional naphtha cracker to make ethylene and propylene. Alternatively, a methanol-to-olefins (MTO) process can be used, based on methanol from syngas [13]. Much remains to be done to identify the optimal conversion routes from syngas through to the various end products. One of the factors that impacts on the optimization of conversion routes is syngas purity [15, ch. 8.2]. Depending on the source of biomass feedstock and the choice of gasifier technology, the raw syngas can contain varying amounts of particulates (e.g. ash or char, which can lead to erosion, plugging or fouling), alkali metals (which can cause hot corrosion and catalyst poisoning), water-soluble trace components (e.g. halides, ammonia), light oils or tars (e.g. benzene, toluene, xylene or naphthalene, which can lead to catalyst carbonization and fouling), polyaromatic compounds, sulphur components, phosphorus components as well as methane and $\mathrm{CO}_{2}$ [1]. Many of these can be removed (if required) at a cost-either using standard chemical-industry equipment such as cyclones, filters, electrostatic precipitators, water scrubbers, oil scrubbers, activated carbon and adsorbents, or via clean-up processes such as hydrolysis and various $\mathrm{CO}_{2}$ capture processes [16,17]. Some of the more intractable areas such as tar removal continue to attract considerable research interest [17]. Another important factor is the ratio of $\mathrm{H}_{2}$ to $\mathrm{CO}$ in the syngas. Different conversion routes require different ratios, e.g. 1.7:1 and 2.15:1 for producing Fischer-Tropsch gasoline and diesel, respectively, or 3:1 for methanol synthesis [13]. Because biomass molecules contain oxygen within their structure, biomass-derived syngas often needs to have its $\mathrm{H}_{2}$ to $\mathrm{CO}$ ratio boosted. One option for achieving this is to react some of the syngas with steam over a catalyst to produce $\mathrm{H}_{2}$ and $\mathrm{CO}_{2}$ in the water-gas shift reaction [10], accepting a $\mathrm{CO}_{2}$ removal cost unless there is a by-product $\mathrm{H}_{2}$ source readily available. The extent to which gas clean-up is required depends on the choice of syngas conversion route. Generally, the level of particulates will need to be reduced to $0.001-0.01 \mathrm{mg} \mathrm{Nm} 23$ for any chemical synthesis process, but the precise extent to which (say) sulphur or halide levels need to be reduced depends on the catalysts that are going to be used. For methanol synthesis process, for example, the sulphur content of the syngas has to be below $100 \mathrm{ppbv}$ [15]. For ammonia synthesis process, there is a similar sulphur constraint, and the $\mathrm{CO}_{2}$ content must be below $10 \mathrm{ppmv}$ [18].

\section{References}

1. Roddy DJ, Manson Whitton C (2012) Biomass gasification and pyrolysis. In Comprehensive renewable energy, biomass and biofuels. DJ Roddy (ed.), The Netherlands: Elsevier, Amsterdam, Netherlands, Europe 5: 133-154.

2. Kwant KW, Knoef H (2004) Status of biomass gasification in countries participating in the IEA bio-energy task 33 biomass gasification and EU gasnet. International Energy Agency Report.

3. Ciferno JP, Marano JJ (2002) Benchmarking biomass gasification technologies for fuels, chemicals and hydrogen production. National Energy Technology Laboratory.

4. Bridgwater AV (2003) Renewable fuels and chemicals by thermal processing of biomass. Chem Eng J 91(2-3): 87-102.

5. E4Tech (2009) Review of technologies for gasification of biomass and wastes. NNFCC project 09/008.

6. Knoef HAM (2005) Handbook of biomass gasification. BTG Biomass Technology Group. Netherlands, Europe PP. 500

7. Jenny B Tennant (2010) Worldwide Gasification Database. National Energy Technology Laboratory, US. 
8. McKendry P. 2001 Energy production form biomass (part 2): conversion technologies. Bioresour Technol 83(1): 47-54.

9. Hotchkiss R (2003) Coal gasification technologies. Proc Inst Mech Eng J Power Energy 217(1): 27-33.

10. Roddy DJ (2013) A syngas network for reducing industrial carbon footprint and energy use. Appl Thermal Energy 53(2): 299-304.

11. Fischer F (1925) Liquid fuels from water gas. Ind Eng Chem 17(26): 574 576.

12. Van Dyk JC, Keyser MJ, Coertzen M (2006) Syngas production from South African coal sources using Sasol-Lurgi gasifiers. Intern J Coal Geol 65(34): 243-253.

13. Spath PL, Dayton DC (2003) Preliminary screening: technical and economic assessment of synthesis gas to fuels and chemicals with emphasis on the potential for biomass-derived syngas. National Renewable Energy Laboratory. Golden, Colorado, US.
14. Evans G, Smith C (2012) Biomass to Liquids technology. In Comprehensive renewable energy, biomass and biofuels. DJ Roddy (ed.), The Netherlands: Elsevier, Amsterdam, Netherlands, Europe 5: 155-204.

15. Higman C, Vander Burgt M (2008) Gasification. UK: Elsevier/GPP, London, UK.

16. Stevens D (2001) Hot gas conditioning: recent progress with larger-scale biomass gasification systems. National Renewable Energy Laboratory, Golden, Colorado, US.

17. Boerrigter H, Den Uil H, Calis HP (2002) Green diesel from biomass via Fischer-Tropsch synthesis: new insights in gas cleaning and process design. In Paper presented at Pyrolysis and Gasification of Biomass and Waste Expert Meeting, Strasbourg, France, Europe.

18. Sutton D, Kelleher B, Ross RH (2001) Review of literature on catalysts for biomass gasification. Fuel Process Technol 73(3): 155- 173.
Creative Commons Attribution 4.0 International License

For possible submissions Click Here

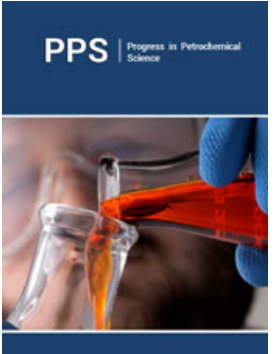

\section{Progress in Petrochemical Science}

\section{Benefits of Publishing with us}

- High-level peer review and editorial services

- Freely accessible online immediately upon publication

- Authors retain the copyright to their work

- Licensing it under a Creative Commons license

- Visibility through different online platforms 